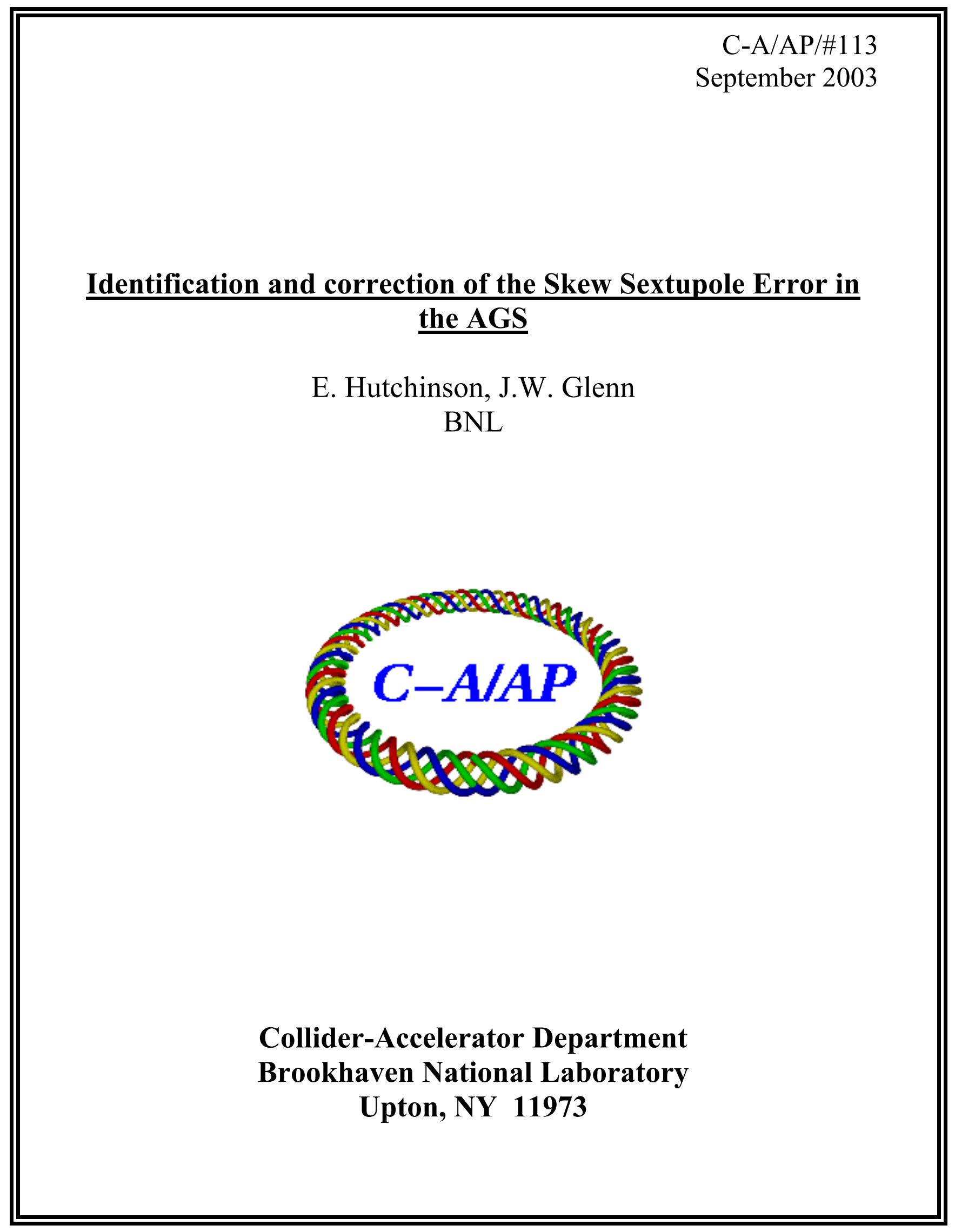




\title{
Identification and Correction of the Skew Sextupole Error in the AGS
}

\author{
E. Hutchinson, J.W. Glenn
}

\begin{abstract}
:
Our aim was to find AGS losses attributable to the $\mathrm{Q}_{\mathrm{y}}=82 / 3$ resonance line and correct for the losses using skew sextupoles. Spanning the year between spring 2002 and spring 2003, the study was completed successfully.

In the spring of 2002 we made an 'intensity map' of the AGS in tune space. We found that it was neither possible to lower the vertical tune below $82 / 3$, nor lower the horizontal tune below $82 / 3$ unless the vertical tune was raised. This behavior is consistent with a skew sextupole perturbation in the AGS field. In 2003 we powered skew sextupoles while driving the vertical tune across the $\mathrm{Q}_{\mathrm{y}}=82 / 3$ resonance line and found reduced losses. The obvious extension of this study, involving the non-linear coupling resonance $2 \mathrm{Q}_{\mathrm{x}}+$ $\mathrm{Q}_{\mathrm{y}}=26$, has yet to be done.
\end{abstract}

Introduction:

In 2002 we sought evidence of the $\mathrm{Q}_{\mathrm{y}}=82 / 3$ resonance in the AGS, by setting the vertical tune to $82 / 3$ and looking for losses. The resonant condition was established at different times in the AGS cycle but was more reproducible at high energy. The skew sextupoles, located at H7, H13, J7, and J13, were connected to two- and six-Amp power supplies. Powering these supplies did not noticeably affect beam loss, as machine instability confused the source of differences in the loss pattern between acceleration cycles. Instead, we looked at the loss rate to estimate the resonance strength and the current necessary to correct for the $82 / 3$ losses at high energy.

A stable machine enabled the collection of reliable data in 2003. Choosing to work at injection energy due to stability issues and using new 20A power supplies, we were able to correct for the losses during the resonance crossing.

Method:

First, we used the tune control program to change the AGS vertical tune to cross $82 / 3$ while holding the horizontal tune constant (see Figure 1). 
We then measured the tune at the time of the crossing, to confirm that it was approximately $82 / 3$. The tune meter was less reliable in 2002 than 2003 .

Where the loss pattern was consistent over several cycles and could be attributed to the tune crossing, we attempted to reduce the beam loss during resonance crossing. We powered the skew sextupoles in different combinations. In 2002 we used all four skew sextupoles; in 2003 with two 20-Amp supplies, we chose two out of the four sextupoles to use at one time.

Results-2002:

In 2002, we created beam loss in the AGS when crossing the $\mathrm{Q}_{\mathrm{y}}=82 / 3$ resonance line, but we were not able to draw conclusions from the loss pattern while the skew sextupoles were powered. We did observe that $90 \%$ of the beam was lost in $30 \mathrm{~ms}\left(10^{4}\right.$ turns $)$ and used this information to calculate the amount of current needed to compensate for the resonance.

We used the following formula from Edwards \& Syphers:

$$
d x / d n=[1 / 4 A / \cos (\theta)]^{*} x^{2}
$$

where $\mathrm{A}$ is the resonance strength and $\mathrm{n}$ is the number of turns. Then, with the equations $\mathrm{S}_{\text {(optical) }}=\mathrm{A} / \beta$ and $\mathrm{S}_{\text {(magnetic) }}=(\mathrm{B} \rho) * \mathrm{~S}_{\text {(optical) }}$, and $\mathrm{B}_{2}{ }^{*} \mathrm{I}=\mathrm{S}_{\text {(magnetic), }}$, we found the amount of current necessary to correct for the resonance.

$$
\begin{gathered}
\text { Given } \beta=22 \mathrm{~m}, \theta=0, \mathrm{x}_{\text {(initial) }}=.001 \mathrm{~m}, \mathrm{x}_{\text {(final) }}=.03 \mathrm{~m}, \\
\mathrm{~B} \rho=80 \mathrm{Tm} \text {, and } \mathrm{B}_{2}=6.6^{*} 10^{\wedge}-3\left(\mathrm{Tm} / \mathrm{m}^{2}\right) / \mathrm{A}, \\
\text { Then } \mathrm{A}=-0.4 \mathrm{~m}^{-1}, \mathrm{~S}_{(\text {optical }}=-1.8^{*} 10^{-2} \mathrm{R} / \mathrm{m}^{2}, \\
\mathrm{~S}_{\text {(magnetic) }}=-1.406 \mathrm{Tm} / \mathrm{m}^{2} \text {, and } \mathrm{I}=-213 \mathrm{~A} .
\end{gathered}
$$

Extrapolating this result to injection energy, we would predict that skew sextupoles running at $20 \mathrm{~A}$ could correct the $\mathrm{Q}_{\mathrm{y}}=82 / 3$ resonance.

Results-2003:

The $82 / 3$ tune crossings produced a $50 \%$ beam loss at the injection field. Using this measurement for comparison, we powered the skew sextupoles in several configurations to see if we could improve transmission. 
Powering the $\mathrm{J} 7$ and $\mathrm{H} 7$ skew sextupoles together reduced losses to $10 \%$ (see Figure 2). Alone J7 reduced losses to 30\% (see Figures 3 and 4). The $\mathrm{H} 7$ and $\mathrm{H} 13$ configurations were less effective, reducing losses to $40 \%$ together and $30 \%$ using only H7. In contrast, the H13 and J13 configurations increased losses to $80 \%$ (see Figure 5).

A full record of the magnets used and their effect on the beam can be seen in the data plots (Figures 6 to 9). These 'contour maps' of loss verses current in various skew sextupoles contain our measurements; the details of the contours are a figment of the MathCAD plotting routine. The low point achieved of 10\% loss [with H7@-5A \& J7@-3.5 A] is seen on Fig 9.

Summary:

Expanding the stable tune space by reducing the effect of resonance lines potentially enables increased particle intensity and allows more latitude maneuvering in tune space to preserve polarization during acceleration. This study was successful in reducing the losses caused by the $3 \mathrm{Q}_{\mathrm{y}}=26$ resonance line. We demonstrated that skew sextupoles running at $10 \mathrm{~A}$ can reduce the effect of skew resonance lines at injection energy. If the error scales with momentum, $\sim 100 \mathrm{~A}$ may be needed at flattop.

In the future this topic should be revisited examining the skew resonance line $2 Q_{x}+Q_{y}=26$ which is a destabilizing resonance potentially close to the working point of the polarized proton program. Repeating this study to measure the correction current needed on flattop would also be of interest. 


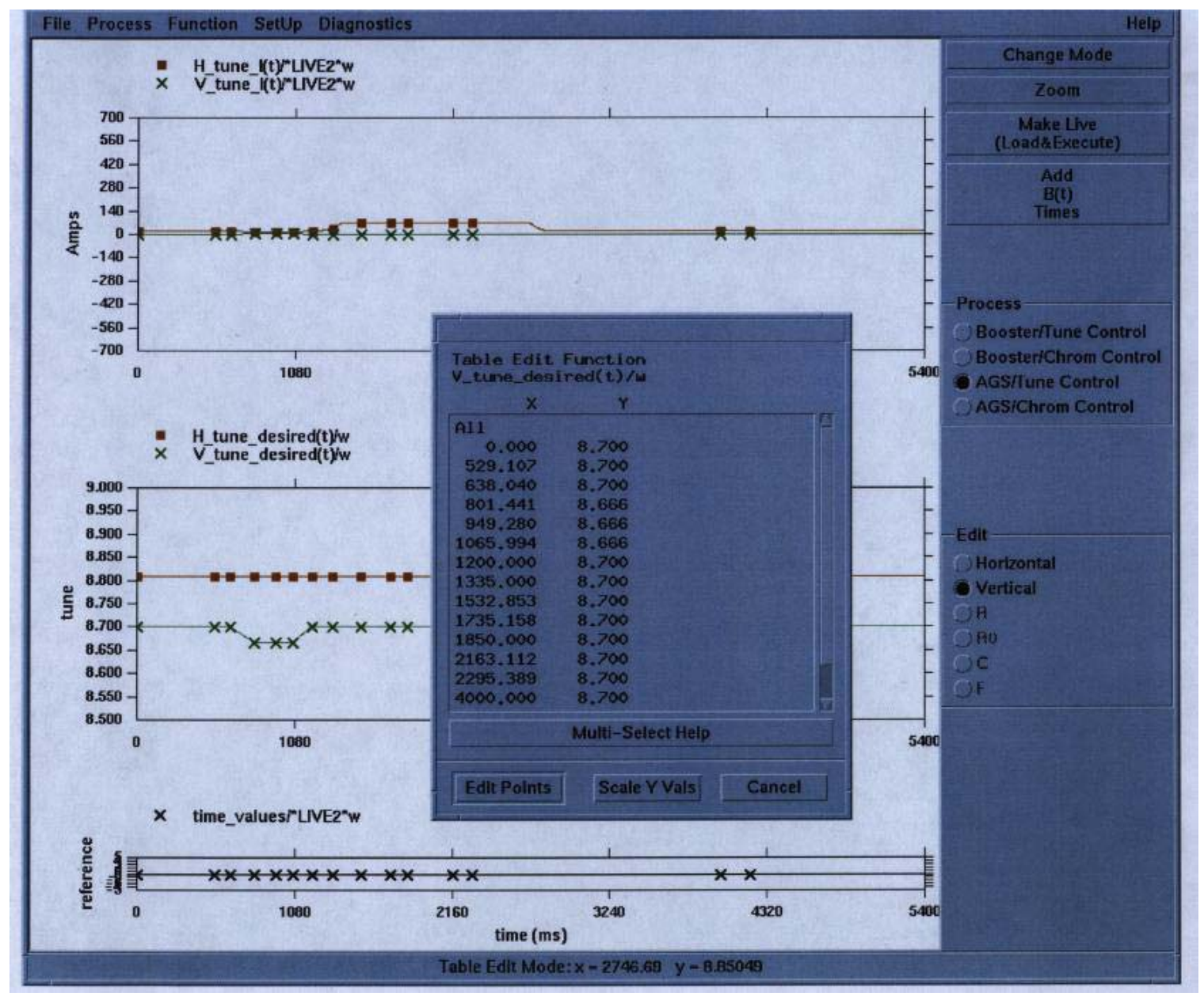

Fig 1. Tune setpoints

In Figures 2-5:

Channel 2 is the vertical tune quadrupole current, during the $82 / 3$ crossing Channel 4 is the beam current transformer signal, while skew sextupoles are powered, as indicated by the description.

Memory $\mathrm{C}$ is the current transformer signal, with no skew sextupoles powered.

Channel 1 (in Figure 5) shows the loss monitor sum 


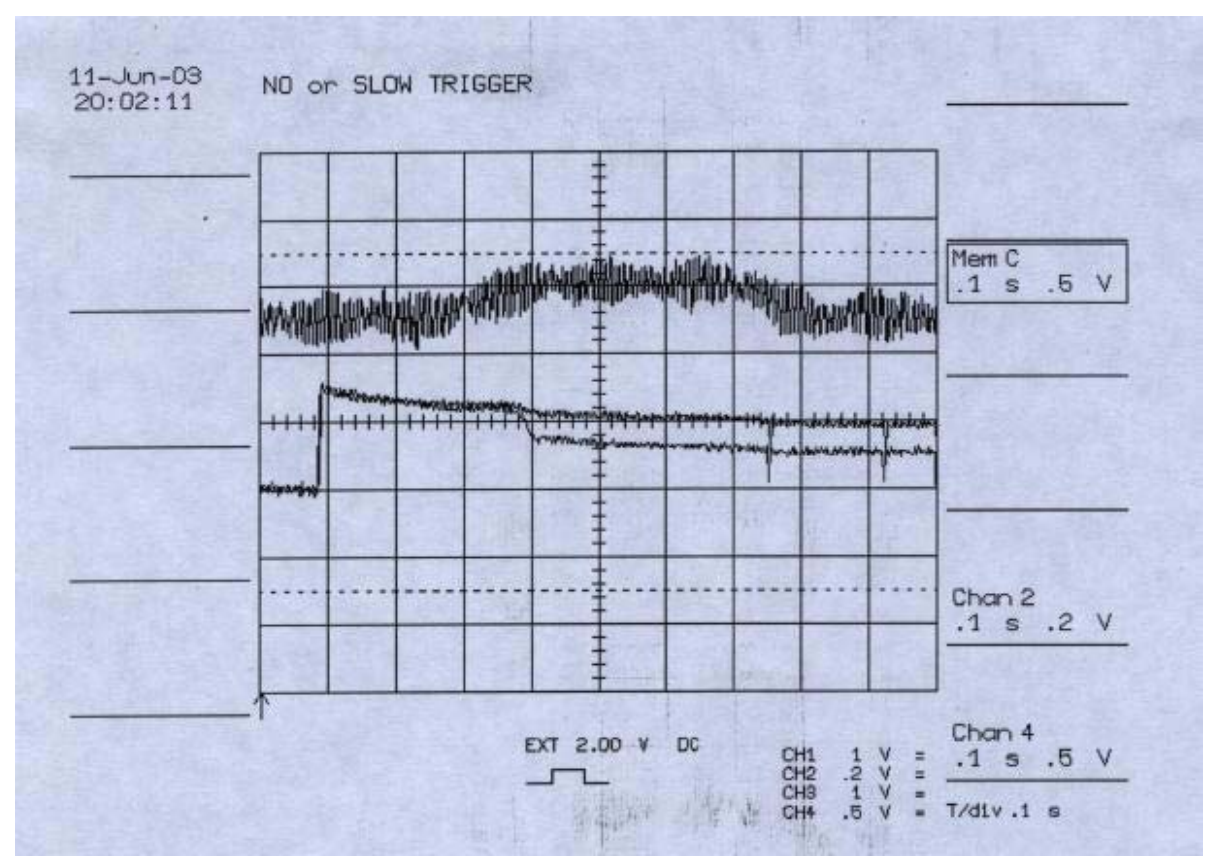

Fig 2. $-5 \mathrm{~A}$ on $\mathrm{J} 7$ and $\mathrm{H} 7$

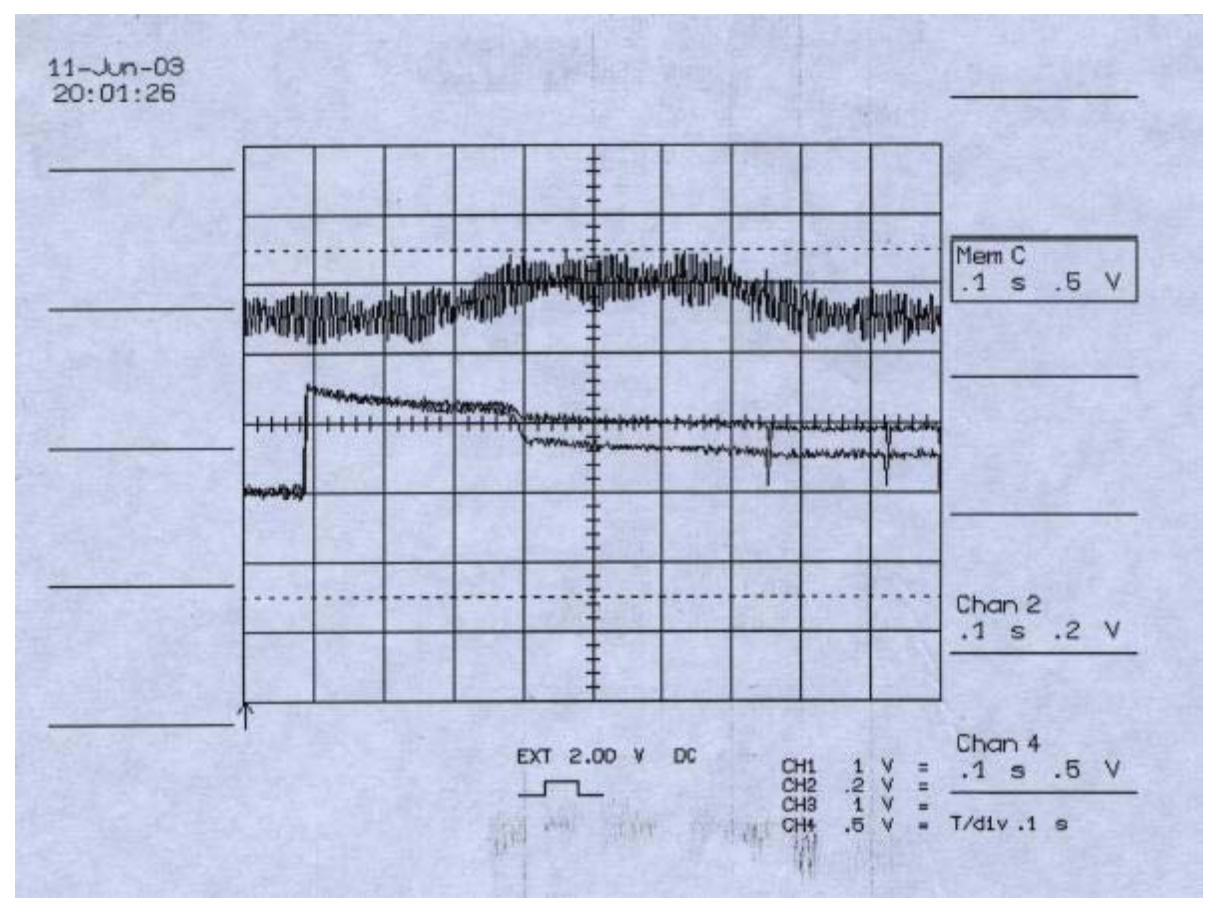

Fig 3. -7A on J7 


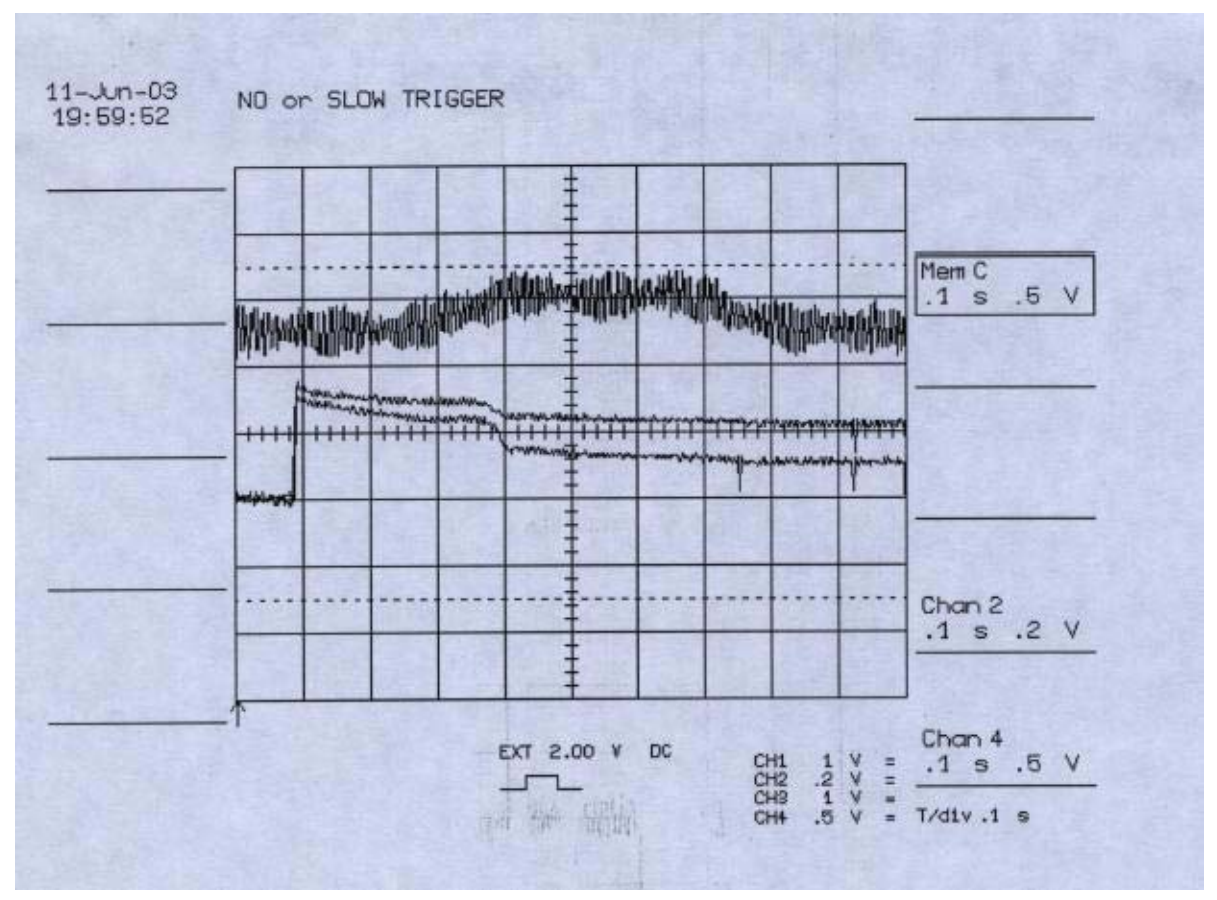

Fig 4. $-10 \mathrm{~A}$ on $\mathrm{J} 7$

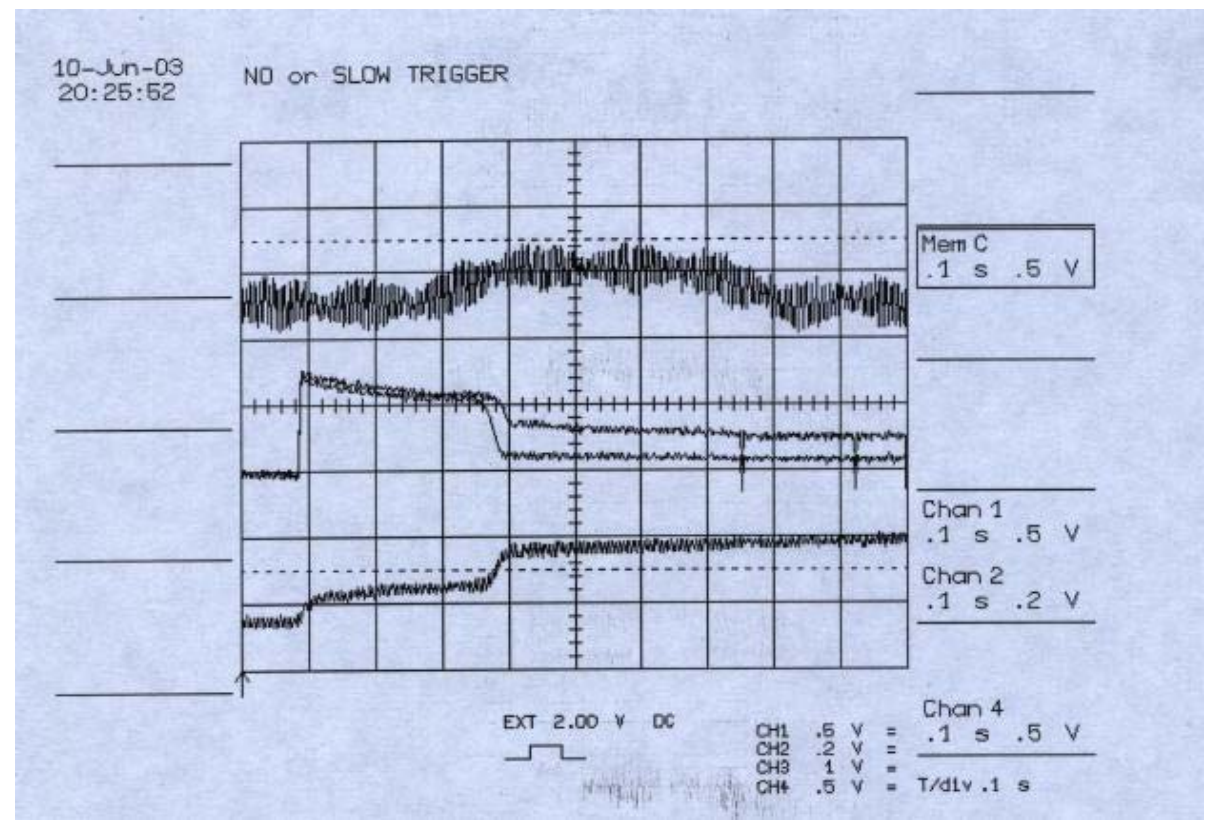

Fig 5. 20A on J13 


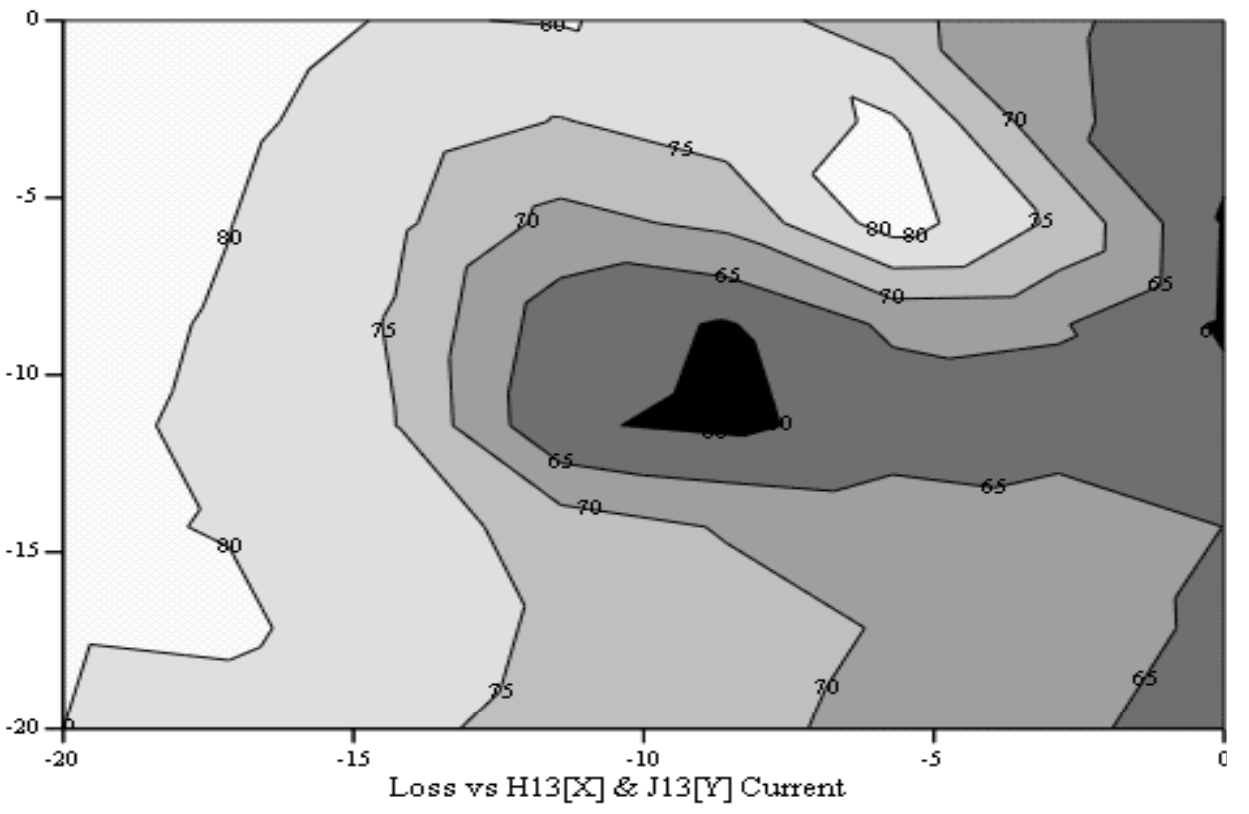

$(\mathrm{X} 1, \mathrm{Y} 1, Z 1)$

Fig 6

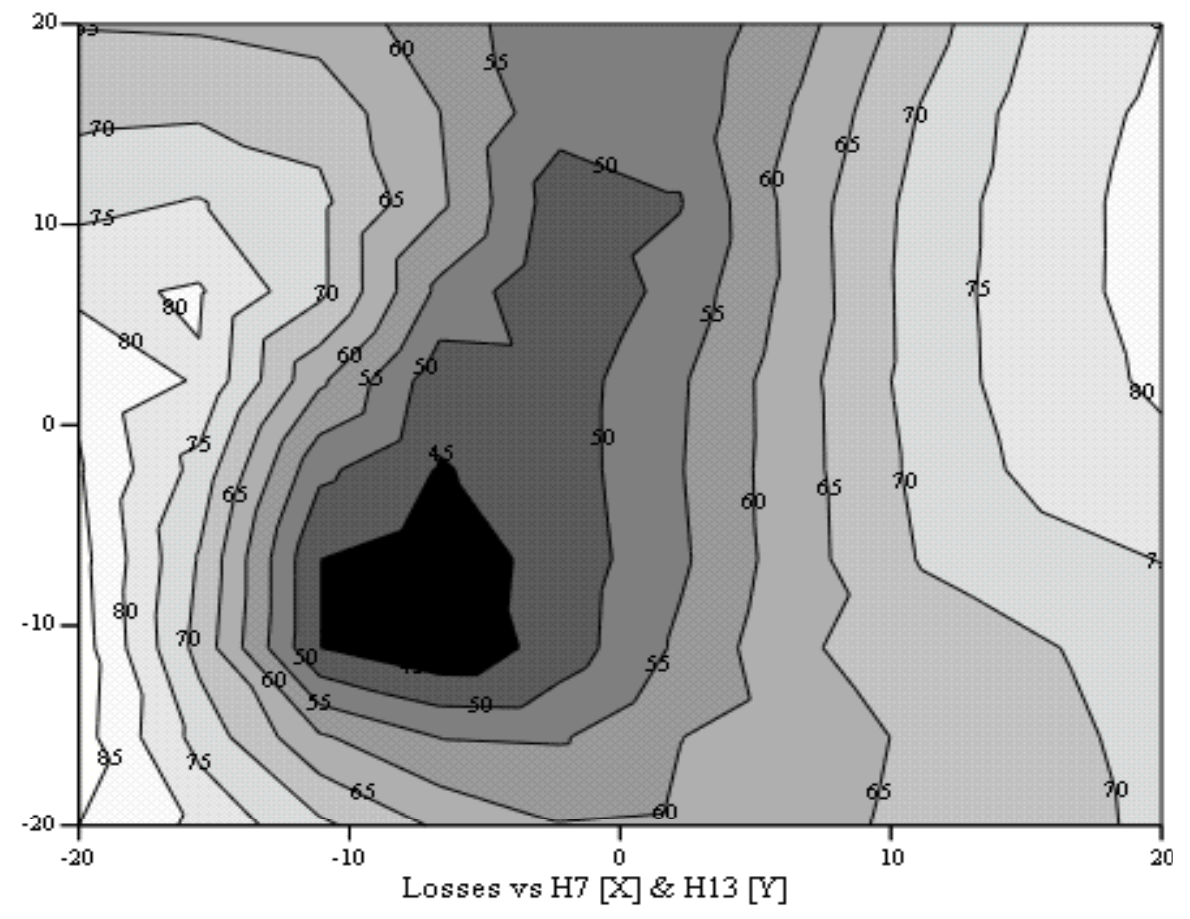

$(\mathrm{X} 2, \mathrm{Y} 2, \mathrm{Z2})$

Fig 7 


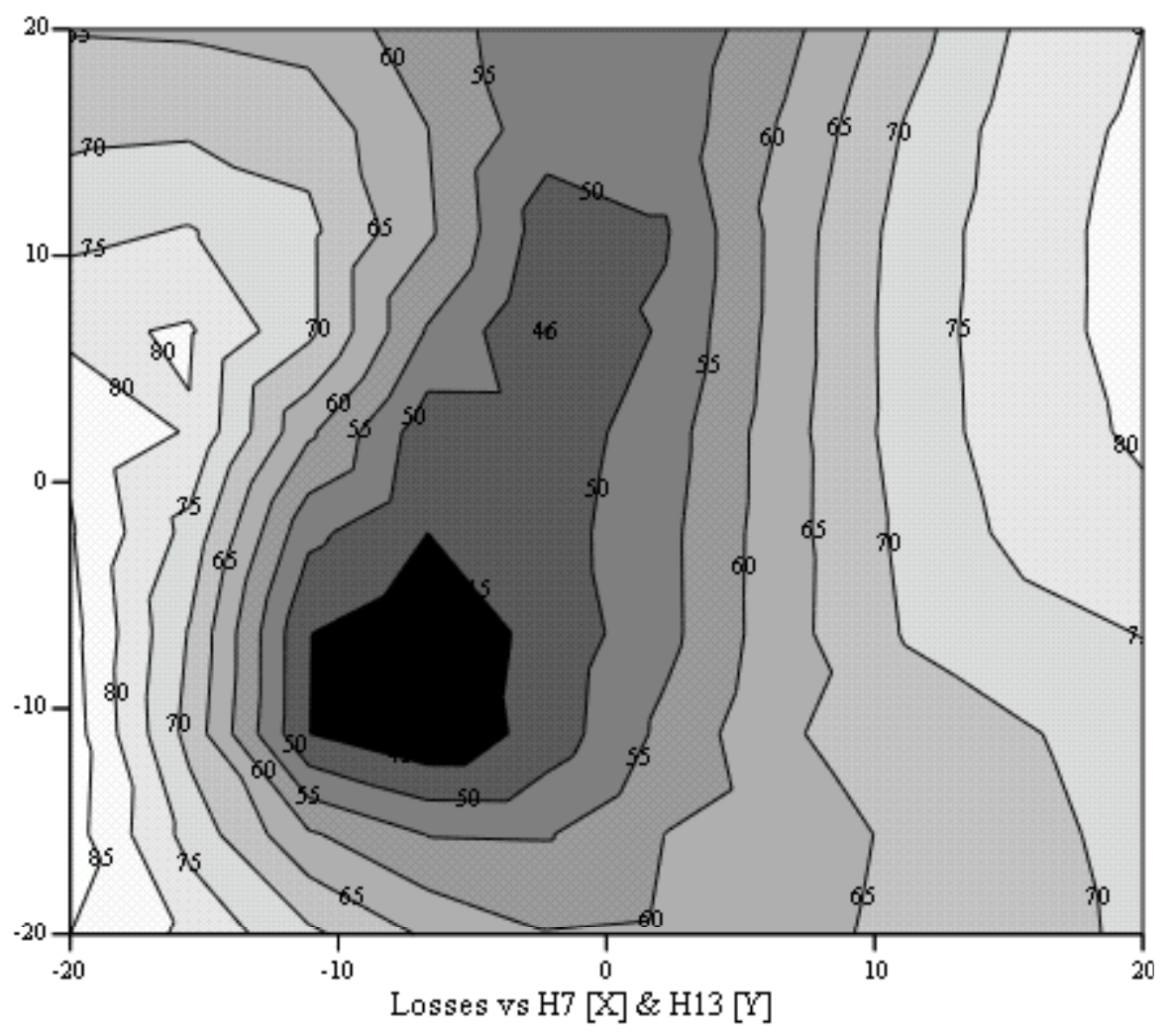

$(\mathrm{X} 2, \mathrm{Y} 2, \mathrm{Z2})$

Fig 8

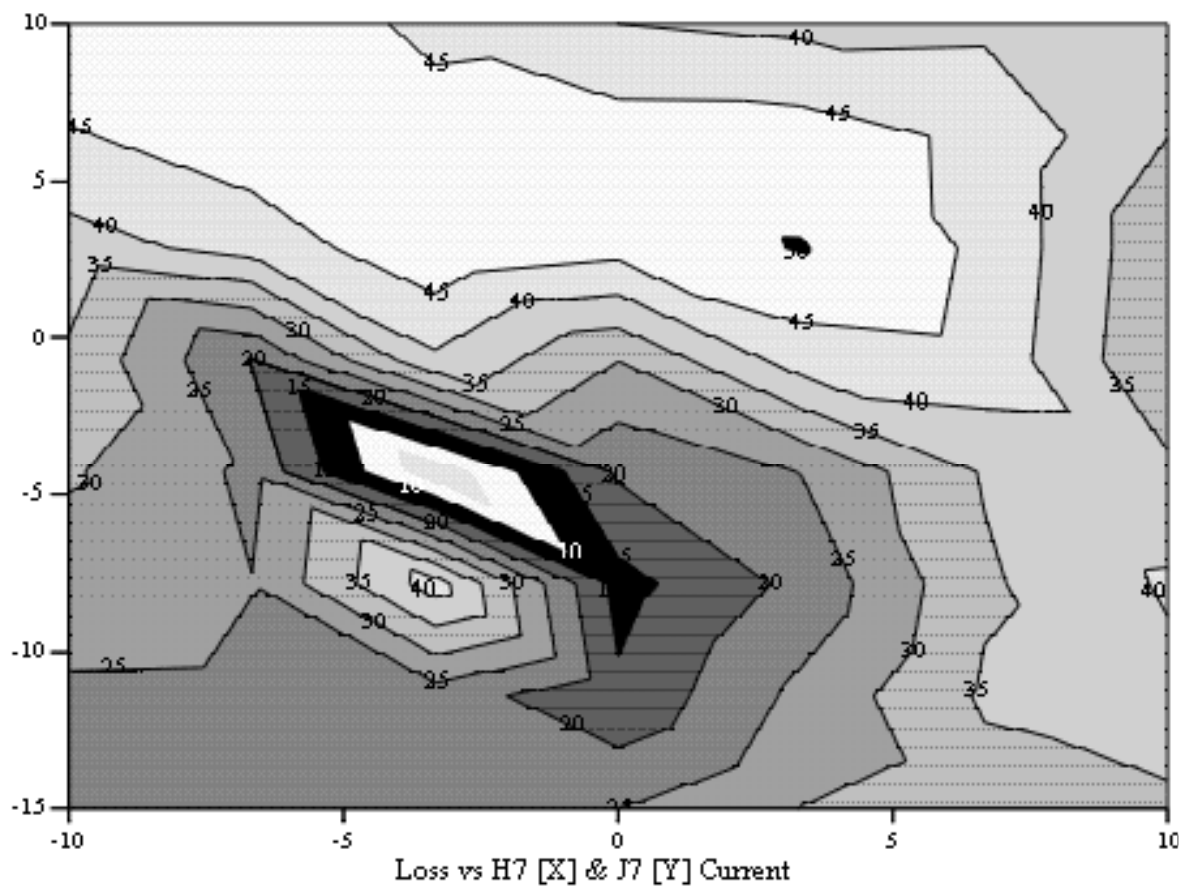

$(\mathrm{X}, \mathrm{Y}, \mathrm{Z})$

Fig 9 